\title{
Effect of Flow Separation Control with Suction Velocity Variation: Study of Flow Characteristics, Pressure Coefficient, and Drag Coefficient
}

\author{
Wawan Rauf ${ }^{1}$, Rustan Tarakka, ${ }^{1, *}$ Jalaluddin $^{1}$, Muhammad Ihsan ${ }^{2}$ \\ ${ }^{1}$ Department of Mechanical Engineering, Hasanuddin University, Makassar, Indonesia \\ ${ }^{2}$ Department of Civil Engineering, Sekolah Tinggi Teknik Baramuli, Pinrang, Indonesia
}

Received December 28, 2019; Revised April 5, 2020; Accepted April 19, 2020

Copyright $\odot 2020$ by authors, all rights reserved. Authors agree that this article remains permanently open access under the terms of the Creative Commons Attribution License 4.0 International License

\begin{abstract}
Flow separation is expected to have the effect of increasing aerodynamic drag due to decreased pressure distribution at the rear of the vehicle. The faster the flow separation occurs, the lower the pressure distribution is in the area, thereby reducing vehicle performance. Therefore, flow modification is needed with expected effects on the separation delay and the reduction in wake and vortex formation. This modification can be done through the application of suction active control in the separation area. The research is intended to analyze the effect of suction active control on flow characteristics, pressure distribution and aerodynamic drag on vehicle models with suction velocity variations. The test model used is an Ahmed model modified by changing the orientation of the flow. The study used a numerical computational approach with a standard k-epsilon turbulence model at $19.4 \mathrm{~m} / \mathrm{s}$ upstream velocity. Results revealed that the use of flow active control was able to reduce wake and vortex formation through separation delay and to increase the minimum pressure coefficient by $73 \%$ on the model with $\mathrm{Usc}_{2}$ suction velocity of $0.5 \mathrm{~m} / \mathrm{s}$, gaining the highest drag coefficient reduction of $10.897 \%$ in the same model.
\end{abstract}

Keywords Active Control, CFD, Drag Coefficient, Flow Characteristics, Flow Separation, Pressure Coefficient

\section{Introduction}

Flow separation is a condition where flow passing through the surface of an object which no longer adheres to the object's surface. Steadily moving flow will split when separation occurs, resulting in a decrease in pressure distribution and the emergence of aerodynamic drag [1]. Reduced distribution of pressure on the rear window and the surface of the vehicle is a major cause of aerodynamic drag, where both locations contribute $90 \%$ of the total resistance and $80 \%$ of it occurs at the rear of the vehicle [2]. Flow separation also results in a pressure difference between the front and rear of the vehicle [3]. The faster the separation occurs, the formation of wake and vortex on the back of the vehicle will be even greater. This has the impacts on reducing vehicle velocity, increasing fuel consumption and leading to lower vehicle performance efficiency [4].

Theoretically, flow separation is a form of the viscous effect of fluids [5]. The viscous effect causes the flow of fluid that reaches the top end of the back of the vehicle to lose kinetic energy so it does not have enough momentum to flow in the boundary layer toward the lower edge of the rear of the vehicle. The large difference in velocity between the wake area and the boundary layer creates a backflow phenomenon [5]. Consideration of flow characteristics in the form of a vortex structure around the vehicle needs to be considered to evaluate the stability of the vehicle while moving [6].

The backflow at the rear of the vehicle triggers suctions rearward. Rearward suction is caused by large pressure differences between the front and the vacuum area that occurs at rear parts of the vehicle [7]. This affects the vehicle's performance due to the effects of aerodynamic drag. Some of the efforts that can be done to increase the pressure coefficient while reducing aerodynamic drag are reducing or delaying flow separation and minimizing the recirculation zone [8,9].

Reduction of wake formation can be done by identifying the location of the flow separation and then applying a suction active control device in the initial location where the separation occurred [10]. Wessen and Thiele [11] 
investigated the effect of using active controls in the form of small holes placed along the upper edge of the rear of the vehicle model. The results showed the use of active controls can increase the average pressure on all parts of the rear wall of the vehicle model and reduce aerodynamic drag by $9.4 \%$.

Gerop and Odhental [9] also examined the effect of active controls placed at the back of the test model. The results showed that the use of active controls was able to increase base pressure by almost $50 \%$, eliminate the recirculation area and reduce aerodynamic drag by $10 \%$.

Roumeas et al. [12] researched a numerical computational approach employing the k-epsilon turbulence model, applied in an Ahmed model with a slant angle of $25^{\circ}$. The Reynolds number used was $2.8 \times 10^{6}$ at $40 \mathrm{~m} / \mathrm{s}$ upstream velocity. The suction active control was placed on the back sloping side. The results showed the use of suction active control could eliminate flow separation and produce reduction in aerodynamic drag close to $17 \%$.

Moussa et al. [13] conducted a study related to the effect of using suction active control on aerodynamic drag of a vehicle model through a numerical computational approach. The results showed the application of suction active control placed on the back side of the vehicle model was effective to reduce the drag coefficient by $9 \%$.

\section{Methods}

The test model used in this study is a modified Ahmed model (reversed Ahmed body) by changing the direction of flow with 0.17 dimension ratio to the original model. Modification of Ahmed models with the application of active control has been extensively researched to describe the flow phenomena occurring around real vehicles [14,15]. The test model dimension has a length of $\mathrm{l}=174 \mathrm{~mm}$, height $\mathrm{h}=48 \mathrm{~mm}$ and width $\mathrm{w}=64.83 \mathrm{~mm}$ with a slope of the front geometry of $25^{\circ}$. Active controls in the form of apertures with $7 \mathrm{~mm}$ diameters are placed on the upper back side of the model. The active control actuation amounts to five apertures with $10.81 \mathrm{~mm}$ distance between them, and designated as suction $1\left(\mathrm{sc}_{1}\right)$, suction $2\left(\mathrm{sc}_{2}\right)$, suction $3\left(\mathrm{sc}_{3}\right)$, suction $4\left(\mathrm{sc}_{4}\right)$ and suction $5\left(\mathrm{sc}_{5}\right)$.
Variations of suction velocity are defined as $\mathrm{Usc}_{1}, \mathrm{Usc}_{2}$, $\mathrm{Usc}_{3}$, and $\mathrm{Usc}_{4}$. The simulation was carried out at an upstream velocity of $19.4 \mathrm{~m} / \mathrm{s}$. Details of the test model and the definition of suction active control are shown in figure 1 and figure 2. The ratio of upstream velocity $\left(\mathrm{U}_{0}\right)$ to suction velocity (Usc) is shown in Table 1.

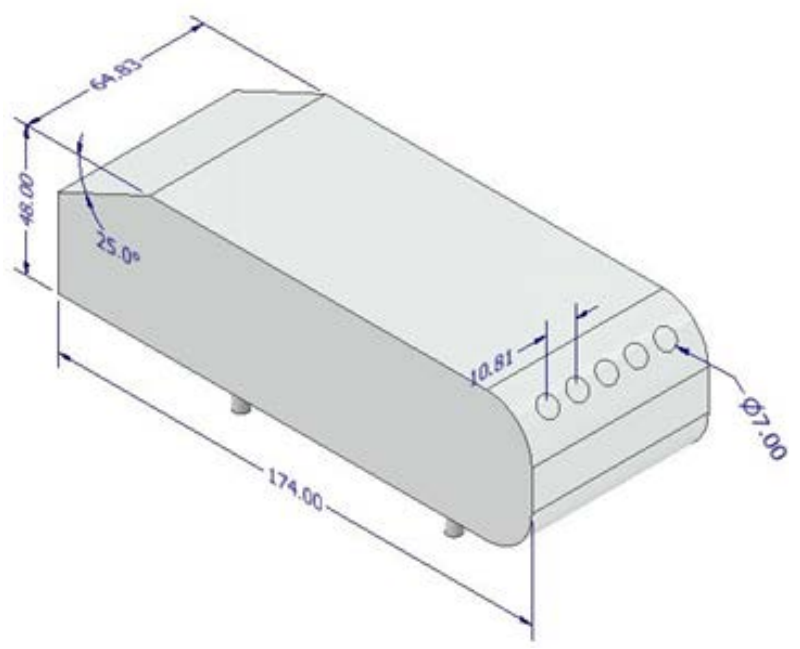

Figure 1. Test model

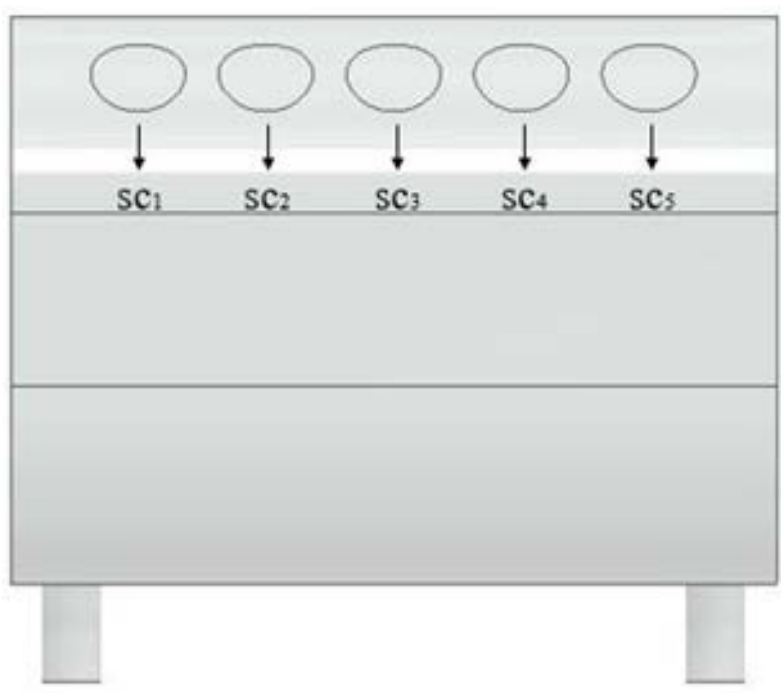

Figure 2. Definition of active controls

Table 1. Ratio of upstream velocity to suction velocity

\begin{tabular}{|c|c|c|c|c|c|c|c|c|c|}
\hline $\mathrm{U}_{0}(\mathrm{~m} / \mathrm{s})$ & Aperture & $\mathrm{Usc}_{1}(\mathrm{~m} / \mathrm{s})$ & $\mathrm{Usc}_{1} / \mathrm{U}_{0}$ & $\mathrm{Usc}_{2}(\mathrm{~m} / \mathrm{s})$ & $\mathrm{Usc}_{2} / \mathrm{U}_{0}$ & $\mathrm{Usc}_{3}(\mathrm{~m} / \mathrm{s})$ & $\mathrm{Usc}_{3} / \mathrm{U}_{0}$ & $\mathrm{Usc}_{4}(\mathrm{~m} / \mathrm{s})$ & $\mathrm{Usc}_{4} / \mathrm{U}_{0}$ \\
\hline \multirow{5}{*}{19.4} & $\mathrm{Sc}_{1}$ & 1.0 & 0.051 & 0.5 & 0.026 & 1.0 & 0.051 & 1.0 & 0.051 \\
\hline & $\mathrm{Sc}_{2}$ & 1.0 & 0.051 & 0.5 & 0.026 & 0.5 & 0.026 & 0.5 & 0.026 \\
\hline & $\mathrm{Sc}_{3}$ & 1.0 & 0.051 & 0.5 & 0.026 & 0.5 & 0.026 & 1.0 & 0.051 \\
\hline & $\mathrm{Sc}_{4}$ & 1.0 & 0.051 & 0.5 & 0.026 & 0.5 & 0.026 & 0.5 & 0.026 \\
\hline & $\mathrm{Sc}_{5}$ & 1.0 & 0.051 & 0.5 & 0.026 & 1.0 & 0.051 & 1.0 & 0.051 \\
\hline
\end{tabular}


The location of the pressure field data collection is determined at five different points according to the number of controls in the ratio of the width of the grid to the width of the model, $\mathrm{z} / \mathrm{w}=-1 / 2, \mathrm{z} / \mathrm{w}=-1 / 4, \mathrm{z} / \mathrm{w}=0, \mathrm{z} / \mathrm{w}=1 / 4$, and $\mathrm{z} / \mathrm{w}=1 / 2$. On models unequipped with active control at each $\mathrm{z} / \mathrm{w}$ location, data were taken at 5 (five) points along the axis of imaginary lines that represent the ratio of the height of the grid to the height of the model, respectively at $\mathrm{y} / \mathrm{h}=0.83, \mathrm{y} / \mathrm{h}=0.67, \mathrm{y} / \mathrm{h}=0.50, \mathrm{y} / \mathrm{h}=0.30$ and $\mathrm{y} / \mathrm{h}=0.17$. For models with active controls, data were taken at each location corresponding to all values of $\mathrm{z} / \mathrm{w}$ along 4 (four) axis lines of $\mathrm{y} / \mathrm{h}=0.67, \mathrm{y} / \mathrm{h}=0.50, \mathrm{y} / \mathrm{h}=0.30$ and $\mathrm{y} / \mathrm{h}=$ 0.17 . Overall, data obtained are at 25 points for models without active control and at 20 points for models with active controls for each suction velocity. Details of the location for taking pressure field data are shown in figure 3 and figure 4.

In this study, the computational approach employed CFD Fluent 6.3 software on standard k-epsilon turbulence model. Initially, the vehicle model is defined into the computational domain and then through the mesh stages using the gambit program. Display mesh and computational domain are shown in figure 5 and figure 6 . The boundary conditions applied in this computational simulation incorporated the upstream velocity of $19.4 \mathrm{~m} / \mathrm{s}$, air density of $1.225 \mathrm{~kg} / \mathrm{m}^{3}$ and air viscosity of $1.7894 \times 10^{-5}$, where the air is assumed to be at steady-state and incompressible flow.

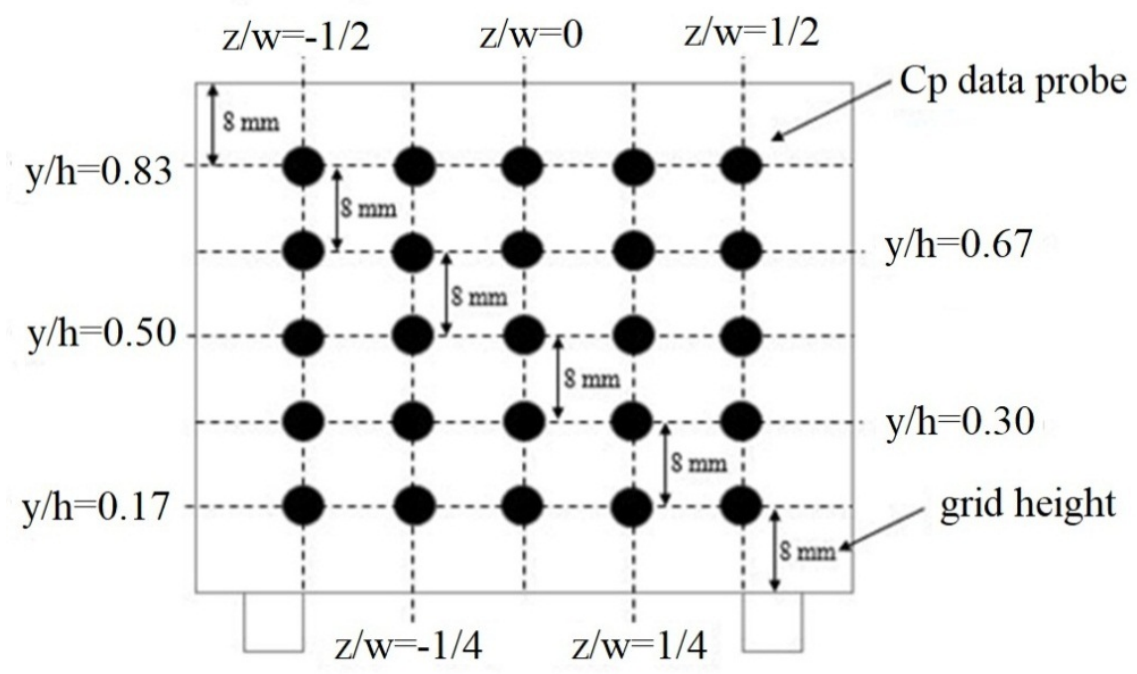

Figure 3. Location of $\mathrm{C}_{\mathrm{p}}$ data acquisition for model without active controls

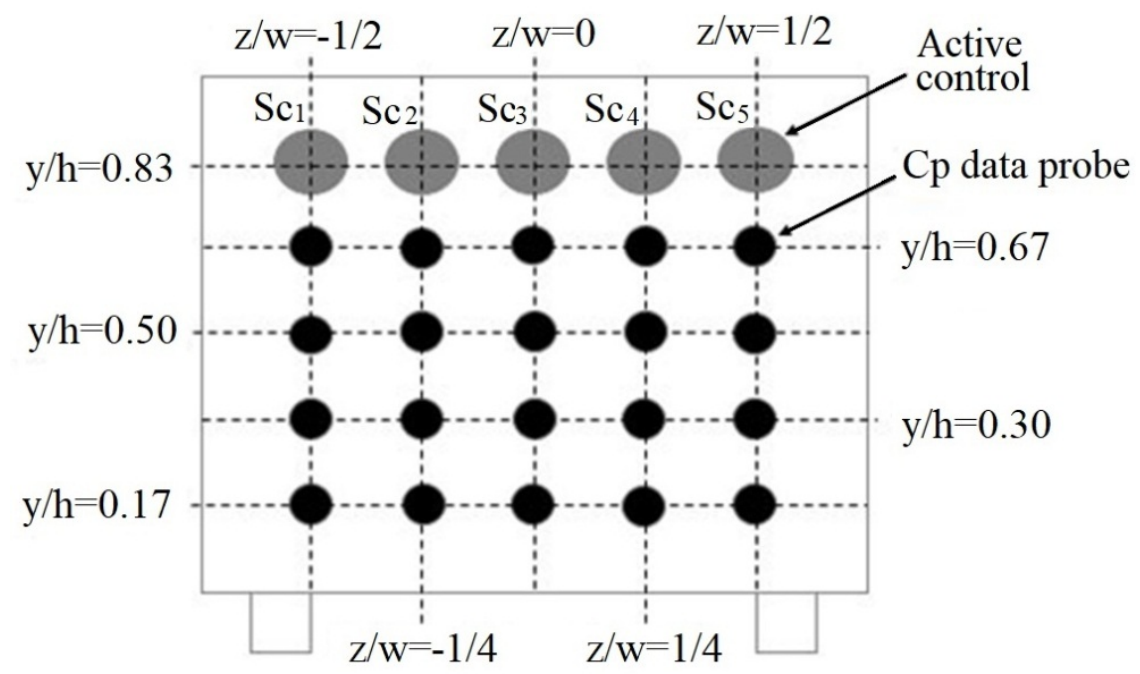

Figure 4. Location of $C_{p}$ data acquisition for model with active controls 


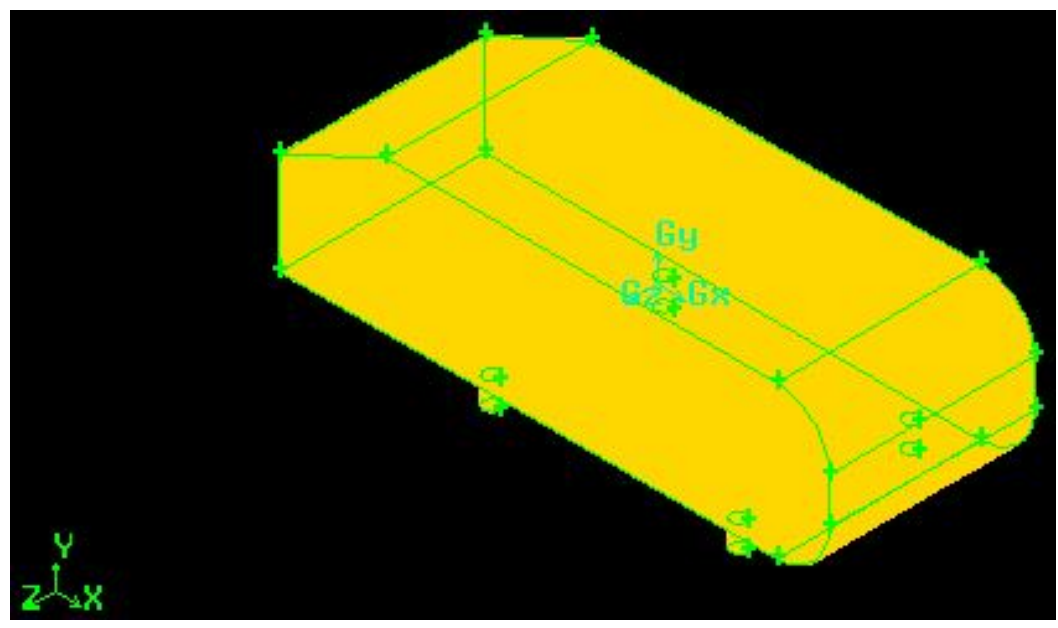

Figure 5. Computational mesh of test model

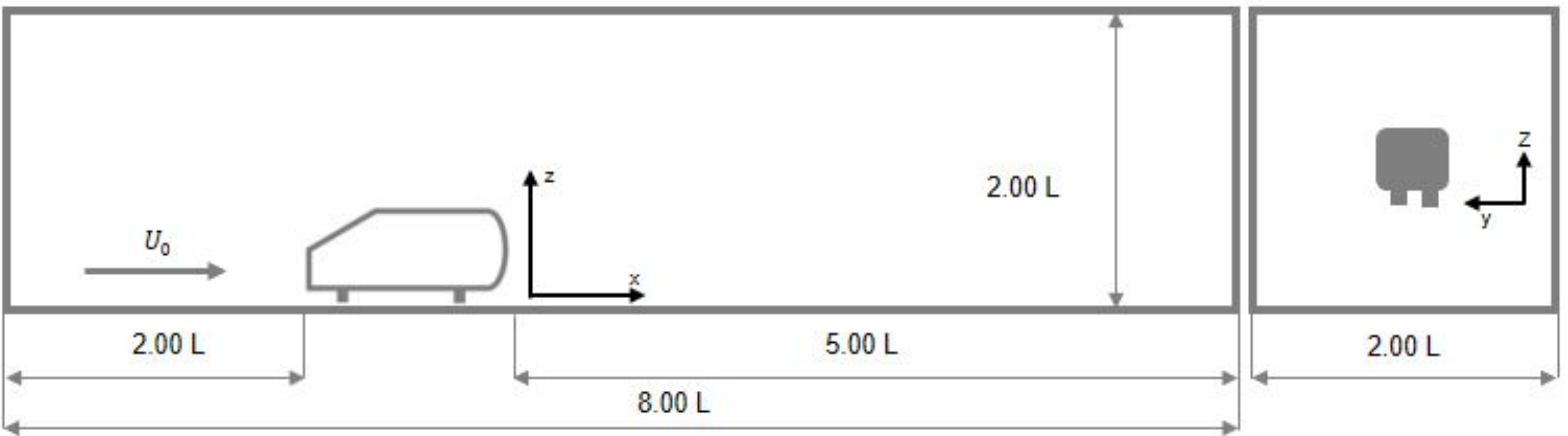

Figure 6. Computational domain

Calculation of the pressure coefficient is written in the relationship of the pressure coefficient with the pressure on the surface of the model $(P)$ and the upstream pressure $\left(\mathrm{P}_{0}\right)$, as shown in equation (1) [5]:

$$
C_{p}=\frac{P-P_{0}}{\frac{1}{2} \rho U^{2}}
$$

The calculation of aerodynamic drag is written in the relationship between the drag coefficient $\left(\mathrm{C}_{\mathrm{d}}\right)$ and drag force $\left(F_{d}\right)$ as denoted in equation (2) [16]:

$$
C_{d}=\frac{F_{d}}{\frac{1}{2} \rho U^{2} A}
$$

\section{Results and Discussions}

\subsection{Flow field}

With the help of FLUENT using the velocity relative to the cell zone motion, the pathlines can be displayed. The concept behind the pathlines generation is the over time integration of particle trace from some starting location and time to some later time step. In this simulation, a $0,01 \mathrm{~m}$ step size of 500 steps is used for node values and relative velocity pathlines. Velocity pathlines for models without active controls and models equipped with active controls $\mathrm{Usc}_{1}, \mathrm{Usc}_{2}, \mathrm{Usc}_{3}$, and $\mathrm{Usc}_{4}$ at an upstream velocity of 19.4 $\mathrm{m} / \mathrm{s}$ are shown in figure $7,8,9,10$, and 11 .

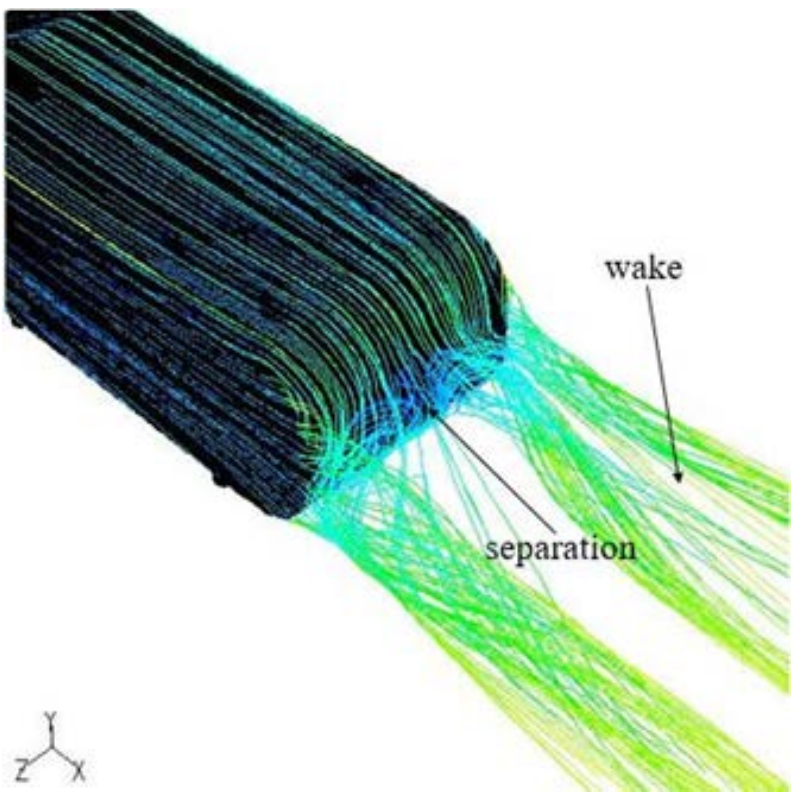

Figure 7. Velocity pathlines of the model without active controls 


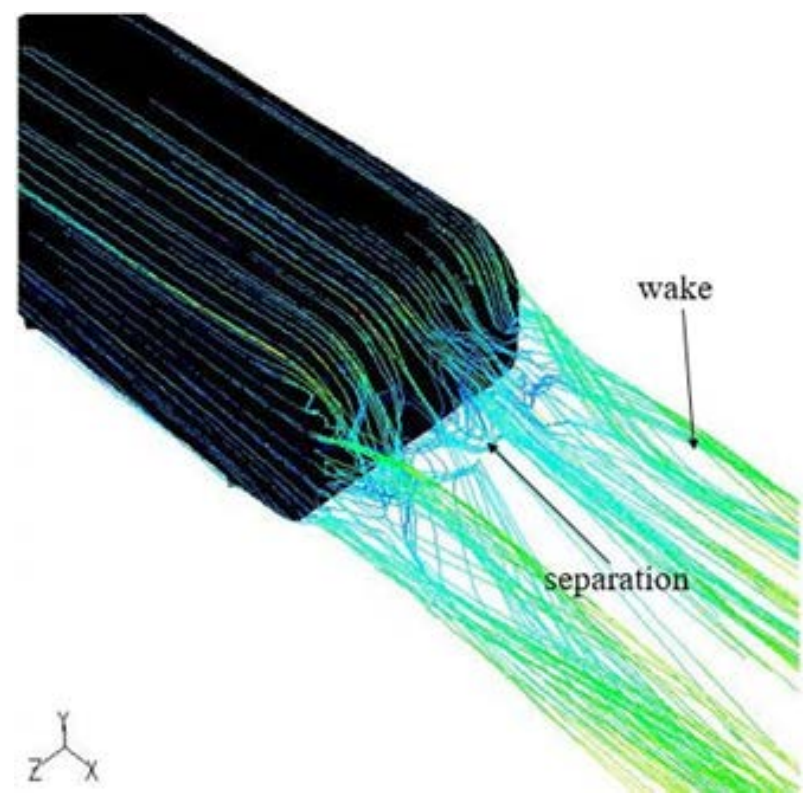

Figure 8. Velocity pathlines of the model with active control $\mathrm{Usc}_{1}$

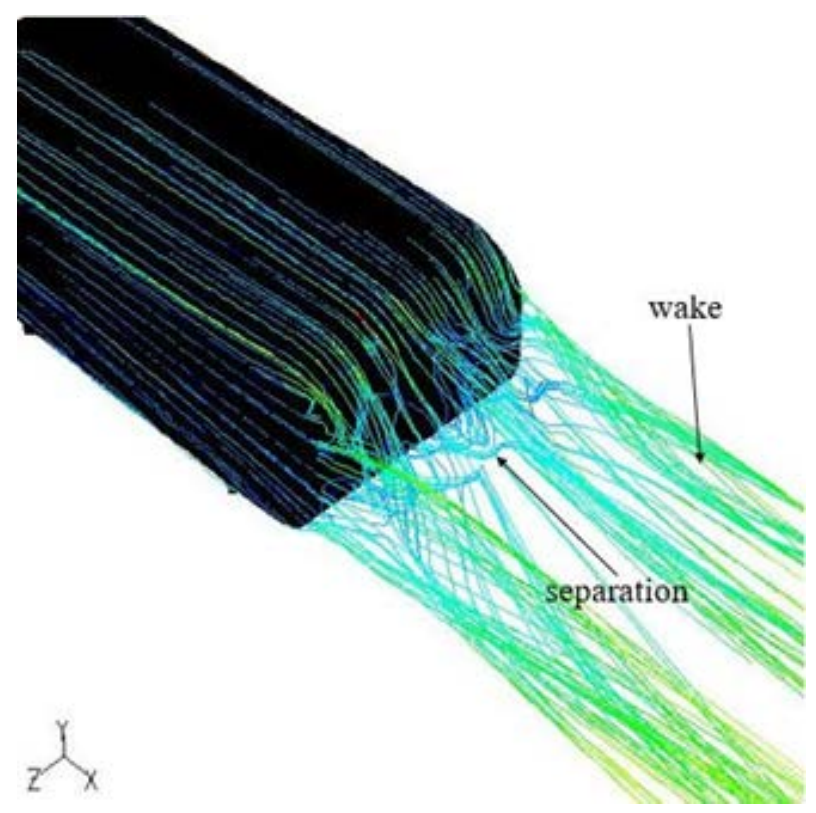

Figure 9. Velocity pathlines of the model with active control $\mathrm{Usc}_{2}$

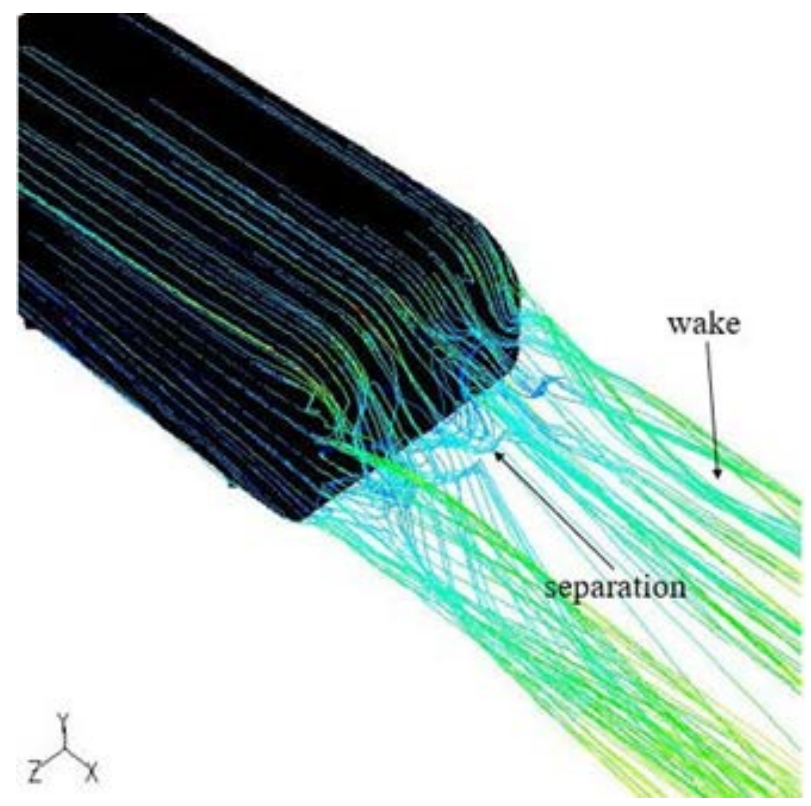

Figure 10. Velocity pathlines of the model with active control $\mathrm{Usc}_{3}$

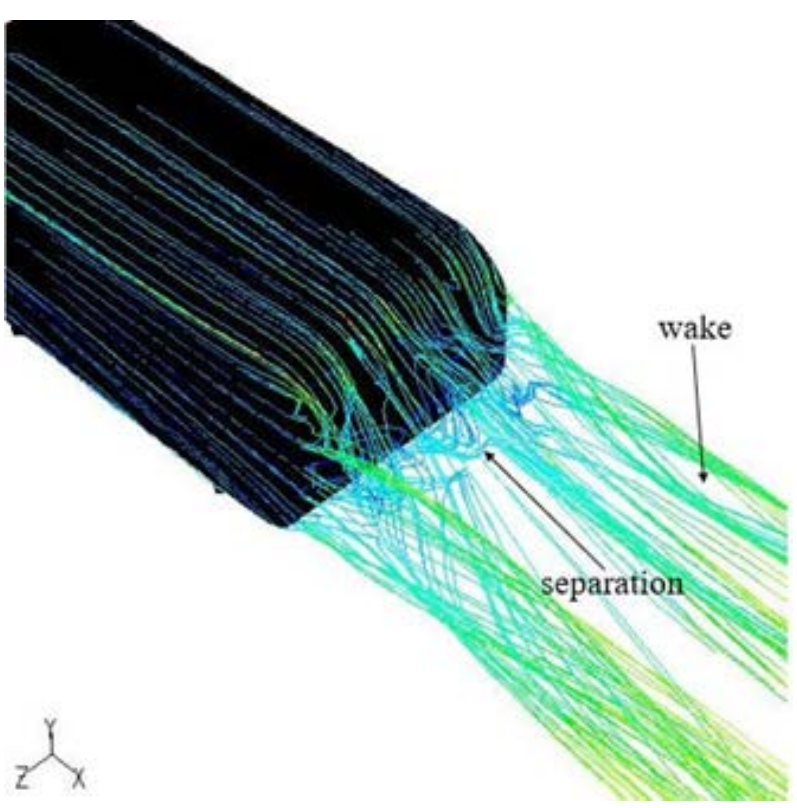

Figure 11. Velocity pathlines of the model with active control $\mathrm{Usc}_{4}$ 
Figures 7, 8, 9, 10, and 11 show the flow separations generated at the back of the vehicle model which results in the formation of wake and vortex. For models unequipped with active controls, the formation of wake and vortex is considerably large and long, due to the separation that occurs right near the back wall of the test model. A fairly large wake phenomenon will cause a rearward suction effect due to a decrease in the pressure coefficient. Wake is also caused by a longitudinal vortex that forms at the top side edges of the back area of the model. Longitudinal vortexes are formed due to differences in flow velocity between the wake area and the side area of the test model [17]. The longer the wake formed, the greater the effect on aerodynamic drag was [18].

On models that use flow control $\mathrm{Usc}_{1}$ suction velocity, the formation of wake and vortex tends to be smaller than that of the models without active controls. This is due to the delay of separation on the back side of the model. Formation of flow separation tends to be on greater distance from the back wall of the model and the flow velocity on the middle side increases when compared to the model without flow active control.

As for models with $\mathrm{Usc}_{2}$ suction velocity, the formation of wake and vortex also tends to be smaller than the one of models without flow control and models with $\mathrm{Usc}_{1}$ suction velocity. The generation of a wake that tends to be small is also caused by delays in flow separation and reduced recirculation areas. The formation of the small wake is seen from the flow pattern formed on the right side of the model shown by the arrow where the wake formation for the $\mathrm{Usc}_{2}$ velocity has a smaller gap and tends to be thin.

For models with $\mathrm{Usc}_{3}$ suction velocity, the formation of wake and vortex is smaller compared to that of models with no active control and models with $\mathrm{Usc}_{1}$ suction velocity. However, it is smaller than that occurring on the model with $\mathrm{Usc}_{2}$ suction velocity. This can be seen from the example of wake formation which has a smaller gap compared to the model without active controls and the model with the Usc ${ }_{1}$ suction velocity. The same situation happened in the $\mathrm{Usc}_{4}$ suction velocity model, where the wake and vortex formation tends to be smaller than that of the model without active control and that with Usc $_{1}$ suction velocity, but it is greater than that of the models with $\mathrm{Usc}_{2}$ and $\mathrm{Usc}_{3}$ suction velocity. A similar study conducted by Harinaldi et al. [19] revealed that suction active control application on the back of the model van had the effect of reducing wake and vortex. This reduction in wake and vortex gives effect on improving overall vehicle performance [20].

\subsection{Pressure Coefficient $\left(C_{p}\right)$}

Minimum pressure coefficients obtained for models without flow control and those equipped with flow control varied in suction velocities $\mathrm{Usc}_{1}$, $\mathrm{Usc}_{2}, \mathrm{Usc}_{3}$, and $\mathrm{Usc}_{4}$ are shown in tables $2,3,4,5$, and 6 .
For models without flow active control, the minimum pressure coefficient is on the upper back side of the model or at the ratio of grid height with model height $\mathrm{y} / \mathrm{h}=0.83$ at all positions for the ratios of grid width to model width, $\mathrm{z} / \mathrm{w}$ as shown in figure 12 . The minimum pressure coefficient value is written down at $\mathrm{z} / \mathrm{w}=-1 / 2$ of $-0.724, \mathrm{z} / \mathrm{w}=-1 / 4$ of $-0.566, \mathrm{z} / \mathrm{w}=0$ of $-0.439, \mathrm{z} / \mathrm{w}=1 / 4$ of -0.566 and $\mathrm{z} / \mathrm{w}=1 / 2$ of -0.566 , the minimum pressure coefficient. This happens because at the position $\mathrm{y} / \mathrm{h}=0.83$, it is the starting point of flow separation and the onset of a backflow phenomenon resulting the pressure coefficient tends to be low in the area. Similar research was also carried out by Anderson [1], finding that the pressure coefficient will be lower in the area where flow separation starts to occur.

Table 2. Minimum pressure coefficients on the vehicle model without active controls

\begin{tabular}{|c|c|c|}
\hline Position & Minimum $\mathrm{C}_{\mathrm{p}}$ & $\mathrm{y} / \mathrm{h}$ position \\
\hline $\mathrm{z} / \mathrm{w}=-1 / 2$ & -0.724 & 0.83 \\
\hline $\mathrm{z} / \mathrm{w}=-1 / 4$ & -0.566 & 0.83 \\
\hline $\mathrm{z} / \mathrm{w}=0$ & -0.439 & 0.83 \\
\hline $\mathrm{z} / \mathrm{w}=1 / 4$ & -0.566 & 0.83 \\
\hline $\mathrm{z} / \mathrm{w}=1 / 2$ & -0.566 & 0.83 \\
\hline
\end{tabular}

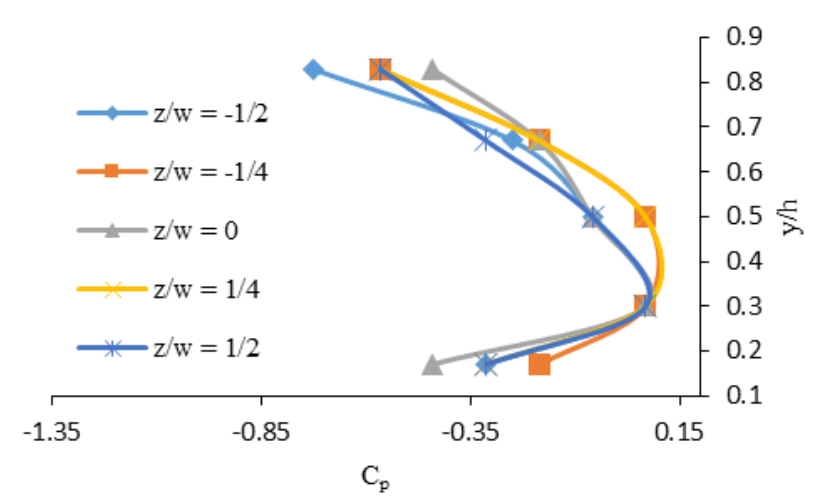

Figure 12. Comparison of minimum $C_{p}$ values to $y / h$ positions on models without active control

For models with $\mathrm{Usc}_{1}$ suction velocity, the minimum pressure coefficient is on the lower side of the back of the vehicle model or in the ratio of grid height to model height, $\mathrm{y} / \mathrm{h}=0.17$ in all positions of ratios of grid width to model width $\mathrm{z} / \mathrm{w}$. Respective values of pressure coefficients are $\mathrm{z} / \mathrm{w}=-1 / 2$ of $-0.182, \mathrm{z} / \mathrm{w}=-1 / 4$ of $-0.182, \mathrm{z} / \mathrm{w}=0$ of -0.325 , $\mathrm{z} / \mathrm{w}=1 / 4$ of -0.268 and for the position $\mathrm{z} / \mathrm{w}=1 / 2$ of -0.239 . The results obtained indicate that there has been a delay in flow separation and minimization of backflow. This can be seen from the increase in the minimum pressure coefficient on the top side of the back of the model and the minimum pressure coefficient moving to the bottom side of the vehicle model. Figure 13 shows the abovementioned result. 
Table 3. Minimum pressure coefficients on the model with Usc $_{1}$

\begin{tabular}{|c|c|c|}
\hline Position & Minimum $\mathrm{C}_{\mathrm{p}}$ & $\mathrm{y} / \mathrm{h}$ position \\
\hline $\mathrm{z} / \mathrm{w}=-1 / 2$ & -0.182 & 0.17 \\
\hline $\mathrm{z} / \mathrm{w}=-1 / 4$ & -0.182 & 0.17 \\
\hline $\mathrm{z} / \mathrm{w}=0$ & -0.325 & 0.17 \\
\hline $\mathrm{z} / \mathrm{w}=1 / 4$ & -0.268 & 0.17 \\
\hline $\mathrm{z} / \mathrm{w}=1 / 2$ & -0.239 & 0.17 \\
\hline
\end{tabular}

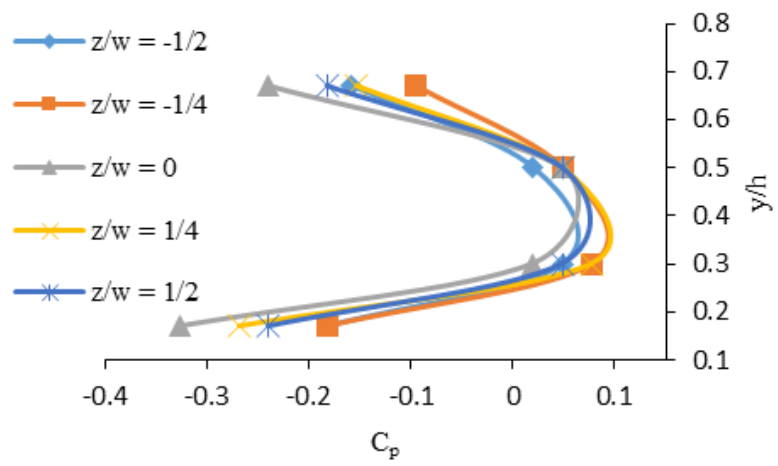

Figure 13. Comparison of the minimum $C_{p}$ value to the position of $y / h$ on the model using active control, $\mathrm{Usc}_{1}$

The minimum pressure coefficient for models without controls is obtained at $\mathrm{y} / \mathrm{h}=0.83$ at all $\mathrm{z} / \mathrm{w}$ positions as it is the starting position of the flow separation process resulting in a decrease in pressure distribution.

The same phenomenon occurs in models with $\mathrm{Usc}_{2}$ suction velocity, where the use of suction active control can increase the minimum pressure, greater than that of models without active control. The minimum pressure coefficient is at the bottom of the back of the vehicle model $(\mathrm{y} / \mathrm{h}=0.17)$, as depicted in figure 14. where the respective values of each position are $\mathrm{z} / \mathrm{w}=-1 / 2$ of $-0.168, \mathrm{z} / \mathrm{w}=-1 / 4$ of -0.168 , $\mathrm{z} / \mathrm{w}=0$ of $-0.195, \mathrm{z} / \mathrm{w}=1 / 4$ of -0.168 and $\mathrm{z} / \mathrm{w}=1 / 2$ of -0.168 . An interesting finding is that the increase in the minimum pressure coefficient on the model with the $\mathrm{Usc}_{2}$ suction velocity is also higher than that of the model with the Usc suction velocity at all positions of the ratio of the grid width to the model width, $\mathrm{z} / \mathrm{w}$.

Table 4. Minimum pressure coefficients on the model with $\mathrm{Usc}_{2}$

\begin{tabular}{|c|c|c|}
\hline Position & Minimum $\mathrm{C}_{\mathrm{p}}$ & $\mathrm{y} / \mathrm{h}$ position \\
\hline $\mathrm{z} / \mathrm{w}=-1 / 2$ & -0.168 & 0.17 \\
\hline $\mathrm{z} / \mathrm{w}=-1 / 4$ & -0.168 & 0.17 \\
\hline $\mathrm{z} / \mathrm{w}=0$ & -0.195 & 0.17 \\
\hline $\mathrm{z} / \mathrm{w}=1 / 4$ & -0.168 & 0.17 \\
\hline $\mathrm{z} / \mathrm{w}=1 / 2$ & -0.168 & 0.17 \\
\hline
\end{tabular}

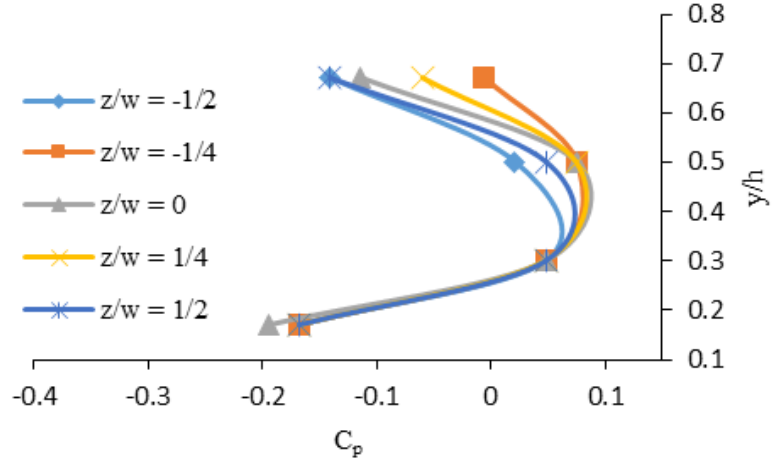

Figure 14. Comparison of the minimum $C_{p}$ value to the position of $y / h$ on the model using active control, $\mathrm{Usc}_{2}$

The model with $\mathrm{Usc}_{3}$ suction velocity showed an increase in the minimum pressure coefficient when compared to the model with no active control and the model with $\mathrm{Usc}_{1}$ suction velocity. But the increase in the minimum pressure coefficient of the model with the $\mathrm{Usc}_{3}$ suction velocity is not higher than that of the model with the $\mathrm{Usc}_{2}$ suction velocity. The lowest pressure, as shown in figure 15 , is also at the bottom of the back of the model $(\mathrm{y} / \mathrm{h}=0.17)$ with each value of $\mathrm{z} / \mathrm{w}=-1 / 2$ of $-0.180, \mathrm{z} / \mathrm{w}=-1 / 4$ of $-0.179, \mathrm{z} / \mathrm{w}=0$ of $-0.210, \mathrm{z} / \mathrm{w}=1 / 4$ of -0.217 and at position $\mathrm{z} / \mathrm{w}=1 / 2$ of -0.177 .

Table 5. Minimum pressure coefficients on the model with $\mathrm{Usc}_{3}$

\begin{tabular}{|c|c|c|}
\hline Position & Minimum $\mathrm{C}_{\mathrm{p}}$ & $\mathrm{y} / \mathrm{h}$ position \\
\hline $\mathrm{z} / \mathrm{w}=-1 / 2$ & -0.180 & 0.17 \\
\hline $\mathrm{z} / \mathrm{w}=-1 / 4$ & -0.179 & 0.17 \\
\hline $\mathrm{z} / \mathrm{w}=0$ & -0.210 & 0.17 \\
\hline $\mathrm{z} / \mathrm{w}=1 / 4$ & -0.217 & 0.17 \\
\hline $\mathrm{z} / \mathrm{w}=1 / 2$ & -0.177 & 0.17 \\
\hline
\end{tabular}

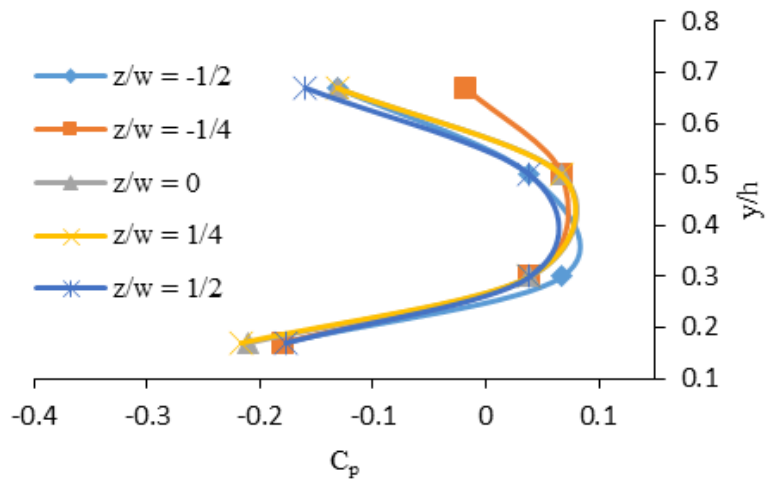

Figure 15. Comparison of the minimum $C_{p}$ value to the position of $y / h$ on the model using active control, $\mathrm{Usc}_{3}$ 
For models with $\mathrm{Usc}_{4}$ suction velocity the minimum pressure coefficient also shifts at the bottom of the rear of the vehicle model $(\mathrm{y} / \mathrm{h}=0.17)$ which is shown on figure 16 . The increase is higher compared to the model with the $\mathrm{Usc}_{1}$ suction velocity, but it is lower compared to the model with the $\mathrm{Usc}_{2}$ and $\mathrm{Usc}_{3}$ suction velocity. The values of pressure coefficient for the position of the ratio of the width of the grid to the width of the model are $\mathrm{z} / \mathrm{w}=-1 / 2$ of -0.181 , $\mathrm{z} / \mathrm{w}=-1 / 4$ of $-0.181, \mathrm{z} / \mathrm{w}=0$ of $-0.215, \mathrm{z} / \mathrm{w}=1 / 4$ of -0.221 and for the position $\mathrm{z} / \mathrm{w}=1 / 2$ of -0.186 .

Table 6. Minimum pressure coefficients on the model with $\mathrm{Usc}_{4}$

\begin{tabular}{|c|c|c|}
\hline Position & Minimum $\mathrm{C}_{\mathrm{p}}$ & $\mathrm{y} / \mathrm{h}$ position \\
\hline $\mathrm{z} / \mathrm{w}=-1 / 2$ & -0.181 & 0.17 \\
\hline $\mathrm{z} / \mathrm{w}=-1 / 4$ & -0.181 & 0.17 \\
\hline $\mathrm{z} / \mathrm{w}=0$ & -0.215 & 0.17 \\
\hline $\mathrm{z} / \mathrm{w}=1 / 4$ & -0.221 & 0.17 \\
\hline $\mathrm{z} / \mathrm{w}=1 / 2$ & -0.186 & 0.17 \\
\hline
\end{tabular}

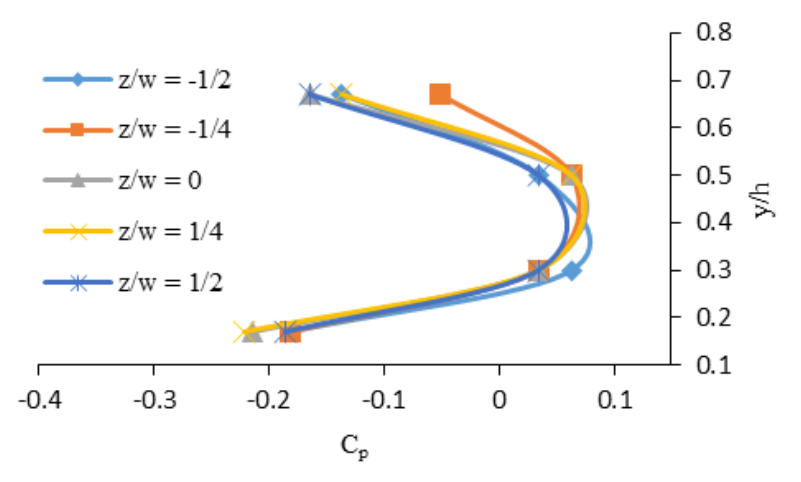

Figure 16. Comparison of the minimum $C_{p}$ value to the position of $y / h$ on the model using active control, $\mathrm{Usc}_{4}$

On all vehicle models with suction active control, the increases in the minimum pressure coefficient are omnipresent. Obtained results indicated a delay in flow separation and minimization of the recirculation wake zone at the back area of the vehicle model as shown in figures 7 , $8,9,10$, and 11 in regard to the flow characteristics. These results are in line with previous research, where the use of flow active control that is positioned at the top edge of the rear of the vehicle model can increase the base pressure [21].

The comparison of the minimum pressure coefficients on the without active control model and the models equipped with active controls with variations suction velocity of $\mathrm{Usc}_{1}, \mathrm{Usc}_{2}, \mathrm{Usc}_{3}$, and $\mathrm{Usc}_{4}$ are shown in table 7.

Table 7 shows the comparison of the increase in the minimum pressure coefficient on models without active control and models that have active controls with variations in suction velocity. The comparison results show an increase of $55.1 \%$ for the model with $\mathrm{Usc}_{1}$ suction velocity. For the suction velocity of $\mathrm{Usc}_{2}, \mathrm{Usc}_{3}$, and $\mathrm{Usc}_{4}$, the pressure coefficient increases by $73.1 \%, 70.0 \%$, and $69.5 \%$, respectively. This shows that the $\mathrm{Usc}_{2}$ suction velocity is the model with the highest minimum pressure coefficient increase.

Table 7. Comparison of minimum pressure coefficients

\begin{tabular}{|c|c|c|c|}
\hline Models & Minimum $\mathrm{C}_{\mathrm{p}}$ & $\mathrm{z} / \mathrm{w}$ position & $\begin{array}{c}\text { Increased } \\
\mathrm{C}_{\mathrm{p}}(\%)\end{array}$ \\
\hline Without control & -0.724 & $-1 / 2$ & - \\
\hline $\mathrm{Usc}_{1}$ & -0.325 & 0 & 55.1 \\
\hline $\mathrm{Usc}_{2}$ & -0.195 & 0 & 73.1 \\
\hline $\mathrm{Usc}_{3}$ & -0.217 & $1 / 4$ & 70.0 \\
\hline $\mathrm{Usc}_{4}$ & -0.221 & $1 / 4$ & 69.5 \\
\hline
\end{tabular}

\subsection{Drag Coefficient $\left(\mathrm{C}_{\mathrm{d}}\right)$}

The comparison of the drag coefficients obtained for models without flow control and using flow control with variations in the suction velocity of $\mathrm{Usc}_{1}, \mathrm{Usc}_{2}, \mathrm{Usc}_{3}$, and $\mathrm{Usc}_{4}$ are shown in table 8.

Table 8. Comparison of drag coefficients

\begin{tabular}{|c|c|c|c|}
\hline Models & $F_{d}(\mathrm{~N})$ & $\mathrm{C}_{\mathrm{d}}$ & Reduction (\%) \\
\hline Without control & 0.7012 & 1.4499 & - \\
\hline Usc $_{1}$ & 0.6278 & 1.2982 & 10.463 \\
\hline Usc $_{2}$ & 0.6248 & 1.2919 & 10.897 \\
\hline $\mathrm{Usc}_{3}$ & 0.6251 & 1.2925 & 10.856 \\
\hline Usc $_{4}$ & 0.6252 & 1.2928 & 10.835 \\
\hline
\end{tabular}

The highest drag coefficient was recorded on the model unequipped with active control at a value of 1.4499 . This happens because the flow separation that occurs at the back of the vehicle model causes the formation of backflow right near the rear wall of the model so that the backward suction phenomenon appears as shown in figure 7. This is in line with research conducted by Gopal and Senthilkumar [22] who found that the main cause aerodynamic drag is the flow separation on the rear wall of the vehicle. For models with Usc $_{1}$ suction velocity, the drag coefficient of 1.2982 occurs, giving a reduction of $10.463 \%$ lower than to the model without active control. On the model with $\mathrm{Usc}_{2}$ suction velocity, a drag coefficient of 1.2919 is obtained or occurred reduction of $10.897 \%$ is obtained. For models with $\mathrm{Usc}_{3}$ and $\mathrm{Usc}_{4}$ suction velocity, each drag coefficient of 1.2925 and 1.2928 or occurred reductions of $10.856 \%$ and $10.835 \%$ are obtained, respectively. The results revealed that the use of flow active control is able to reduce the drag coefficient, where the greatest reduction was recorded on the model with $\mathrm{Usc}_{2}$ suction velocity of $10.897 \%$. This is in line with the results obtained on the flow pattern characteristics and the increase in the pressure coefficient which shows that the model with the $\mathrm{Usc}_{2}$ suction velocity is the model that produces the smallest wake and vortex as shown in figure 9 and the highest increase in the minimum pressure coefficient as shown in table 7. These results are in line with research conducted by 
Tarakka et al. [23] which found that the use of active controls on vehicle models is capable in reducing aerodynamic drag. The application of flow separation control is also able to improve overall vehicle performance [24].

\section{Conclusions}

A. The application of suction active control can reduce the formation of wake and vortex, where the greatest reduction is obtained on the model with $\mathrm{Usc}_{2}$ suction velocity of $0.5 \mathrm{~m} / \mathrm{s}$.

B. The use of suction active control is also able to increase the minimum pressure coefficient, where the greatest increase in the minimum pressure coefficient of $73.1 \%$ is obtained on the model with an $\mathrm{Usc}_{2}$ suction velocity of $0.5 \mathrm{~m} / \mathrm{s}$.

C. The use of suction active control gives an effect on the reduction of the drag coefficient, where the highest reduction in the drag coefficient of $10.897 \%$ is obtained on the model with an $\mathrm{Usc}_{2}$ suction velocity of $0.5 \mathrm{~m} / \mathrm{s}$.

\section{Acknowledgements}

We are very grateful to the Head of Fluid Mechanics Laboratory and Faculty Members of Mechanical Engineering Department, Hasanuddin University for their support and financial assistance.

\section{REFERENCES}

[1] J. D. Anderson. Fundamental of Aerodynamics, McGraw-Hill, University of Mayland, United states, 2001.

[2] A. Kourta, P. Gillieron. Impact of the automotive aerodynamic control on the economics issues. Journal of Applied Fluid Mechanics, Vol. 2, pp. 69-75, 2009.

[3] W. H. Hucho. Aerodynamics der stumpfen K oprer-Physicalische Grundlagen und Anwendung in der Praxis, Vieweng-Verlag, 2002.

[4] T. Ragavan, S. Palanikumar, D. Anastraj, R. Arulalagan. Aerodynamic Drag Reduction on Race Cars, Journal of Basic and Applied Engineering Research, Vol. 1, No. 4, 99103, 2014.

[5] B. R. Munson, D. F. Young, T. H. Okiishi. Fluid Mechanics, Fourth Edition, 2002.

[6] T. Nakashima, M. Tsubokura, T. Nouzawa, T. Nakamura, H. Zhang, N. Oshima. Large-Eddy Simulation of Unsteady Vehicle Aerodynamics and Flow Structures. Bluff Bodies Aerodynamics \& Applications, VI International Colloquium, Milano, Italy, July, 20-24, 2008.

[7] T. B. Hilleman. Vhicle drag reduction with air scoop vortex impeller and trailing edge surface texture treatment. United State Patent No.: US 7, 192,007 BI. Mar. 20, 2007.

[8] S. M. R. Hassan, T. Islam, M. Ali, Md. Q. Islam. Numerical Study on Aerodynamic Drag Reduction of Racing Cars, 10th International Conference on Mechanical Engineering ICME, Procedia Engineering, Vol. 90, pp. 308-313, 2014.

[9] D. Gerop, H. J. Odhenthal. Drag reduction of motor vehicles by active flow control using the Coanda effect. Springer-Verlag, Experiments in Fluids, Vol. 28, pp. 74-85, 2000.

[10] R. Kumar B, N. Varshan M, Kannan. T. Aerodynamics design optimization of an automobile car using computational fluid dynamics approach. Australian Journal of Mechanical Engineering, DOI: 10.1080/14484846.2019. 1654963.

[11] E. Wessen, F. Thiele. Road Vehicle Drag Reduction by Combined Steady Blowing and Suction, $39^{\text {th }}$ AIAA Fluid Dynamics Conference, pp. 1-9, 2009.

[12] M. Roumeas, P. Gillieron, A. Kourta. Drag reduction by flow separation control on a car after body, International Journal for Numerical Methods in Fluids, 2009.

[13] A. A. Moussa, R. Yadav, J. Fischer. Aerodynamic Drag Reduction for A Generic Sport Utility Vehicle Using Rear Suction, Journal of Engineering Research and Applications, Vol. 4, Issue 8 (Version 7), pp. 101-107, 2014.

[14] R. Tarakka, Jalaluddin, B. Mire, M. N. Umar. Effect of Turbulence Model in Computational Analysis of Active Flow Control on Aerodynamic Drag of Bluff Body Van Model, International Journal of Applied Engineering Research, Vol. 10, No. 1, pp. 207-219, 2015.

[15] Harinaldi, Budiarso, R. Tarakka, S. P. Simanungkalit. Computational Analysis of Active Flow Control to Reduce Aerodynamics Drag on a Van Model, International Journal of Mechanical \& Mechatronics Engineering IJMME-IJENS, Vol. 11, No. 03, 2011.

[16] Y. A. Cengel, J. M. Cimbala. Fluid Mechanics: Fundamental and Applications, McGraw Hill, 2014.

[17] Harinaldi, Budiarso, Warjito, E. A. Kosasih, R. Tarakka, S. P. Simanungkalit. Active Technique by Suction to Control the Flow Structure Over a Van Model, AIP Converence Proceedings, pp. 1333-1339, 2012.

[18] G. Bonnavion, O. Cadot, A. Évrard, V. Herbert, S. Parpais, R. Vigneron, J. Délery. On Multistabilities of Real Car's Wake, Elsevier, Journal of Wind Engineering and Industrial Aerodynamics, pp. 22-33, 2017.

[19] Harinaldi, Budiarso, Warjito, E. A. Kosasih, R. Tarakka, S. P. Simanungkalit, I. G. M. F. L. Teryanto. Modification of flow structure over a van model by suction flow control to reduce aerodynamics drag. MAKARA, Teknology, Vol. 16, No. 1, pp. 15-21, 2012.

[20] S. Hetawal, M. Gophane, Ajay B. K, Y. Mukkamala. Aerodynamic Study of Formula SAE Car, $12^{\text {th }}$ Global Congress On Manufacturing and Management, GCMM, 1198-1207, 2014.

[21] S. Krajnovic, J. Fernandes. Numerical simulation of the flow around a simplified vehicle model with active flow control. International Journal of Heat and Fluid Flow, Vol. 32, 
pp.192-200, 2011.

[22] P. Gopal, T. Senthilkumar. Influence of Wake Characteristics of a Representative Car Model by Delaying Boundary Layer Separation, Journal of Applied Science and Engineering, Vol. 16, No. 4, pp. 363-374, 2013.

[23] R. Tarakka, N. Salam, Jalaluddin, M. Ihsan. Effect of Blowing Flow Control and Front Geometry Towards the Reduction of Aerodynamic Drag on Vehicle Models, FME Transaction, Vol. 47, No. 3, pp. 552-559, 2019.

[24] D. G. Hyams, K. Sreenivas, R. Pankajakshan, D. S. Nichols, W. R. Briley, D. L. Whitfield. Computational Simulation of Model and Full Scale Class 8 Trucks with Drag Reduction Devices, Elsevier, Computers \& Fluids, Vol. 41 No. 1, pp. 27-40, 2011. 